\title{
Role of ginger (zingiber officinale) against metalaxyl induced hepatotoxicity in male albino rats: a histological and immunohistochemical study
}

Nabila M. El-Ghonaimy

Correspondence: nabilam.alghonamy@yahoo.com

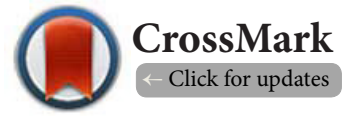

Department of Histology and Cell Biology, Faculty of Medicine, Zagazig University, Zagazig 44519, Egypt.

\begin{abstract}
Background: Metalaxyl is a fungicide used to control soil-borne fungal diseases on fruits, cotton, soy bean, peanuts and grasses. Food contamination with metalaxyl is a worldwide problem especially in developing countries. Ginger has antioxidant properties.

Aim of the work: To elucidate the histological alterations that may occur in the liver tissue of rat by metalaxyl and to investigate the role of ginger supplementation against these alterations.

Materials and methods: Thirty healthy adult male albino rats were used in this study. They were equally divided into three groups:

Group I served as control group. Group II (metalaxyl-treated) received $130 \mathrm{mg} / \mathrm{kg}$ body weight/day of metalaxyl dissolved in distilled water using a gastric tube for 3 times/week for continuous 4weeks. Group III (metalaxyl-ginger treated group) received metalaxyl as group II in addition to ginger given orally at a dose of $100 \mathrm{mg} / \mathrm{kg}$ three times/week for successive 4 weeks. At the end of experiment, all rats were anaesthetized and liver specimens were taken and processed for light and electron microscope examination. Immunohistochemical staining was carried out for detection of the proapoptotic marker Bcl-2 antagonist-X $(\mathrm{BAX})$ protein in hepatocytes. Area \% of BAX protein was measured and statistically analyzed.

$\underline{\text { Results: }}$ Examination of the liver sections of metalaxyl-treated group II showed different degrees of focal lobular affection. Central veins and blood sinusoids were dilated and congested. The hepatic lobules lost their normal architecture and the hepatocytes showed cytoplasmic vacuolization with darkly stained nuclei. Enlarged portal areas with numerous bile ductules and cellular infiltration were detected. Ultrastrcturally, hepatocytes had condensed heterochromatin nuclei and electron lucent areas were observed in their cytoplasm. Significant increase in area \% of positive immunoreaction for BAX was detected in comparison with control group and group III. Examination of liver sections of group III revealed preservation of nearly normal histological structure with slight congested blood vessels and few cellular infiltration.
\end{abstract}

Conclusion: Metalaxyl had pathological effects on the structure of rat's liver and these effects were decreased by ginger.

Keywords: Metalaxyl, ginger, liver histology, ultrastructure, rat

\section{Introduction}

Metalaxyl is a benzenoide fungicide that widely used in developing countries; it is used to protect crops against soil-borne pathogens [1]. The problems resulting from metalaxyl come from their high residual level in agriculture crops especially vegetables cultivated under greenhouse conditions and during storage and germination of seed grain $[2,3]$. Dasgupta et al., [4] reported that residues of buprafezin, chlorpyriphas, metalaxyl and mychobutanil were detected in cured grapes and wine samples.

Metalaxyl was reported to have cytogenetic effects on human and animal chromosomes in vitro [5] and Demsia et al., [6] 
Nabila M. EI-Ghonaimy, Journal of Histology \& Histopathology 2015,

found that imidaclopride and metalaxyl have genotoxic effects as they induced micronucleus formation in human lymphocytes in vitro and in polychromatic erythrocytes of the rat's bone marrow in vivo.

AL-Amoudi [7] detected hematological effects and cocarcinogenic potential of metalaxyl in Swiss albino mice. Reproductive toxicity of metalaxyl and mancozeb in adult male albino rat was detected by Rao et al., [8] and Mehra et al., [9]. Recent published studies have reported that metalaxyl toxicity may be associated with the enhanced production of reactive oxygen species (ROS). The production of ROS is caused by a mechanism in which xenobiotics, toxicants and pathological conditions may produce oxidative stress. If ROS formation exceeds the capacity of antioxidants, ROS react with macro-molecules such as lipid, protein and DNA causing cell dysfunction and damage [10].

Ginger (Zingiber officinal Roscoe) is an example of botanicals which gains popularity amongst modern physicians and its underground rhizomes are medicinally useful parts [11].

One of the most popular uses of ginger is to relief the symptoms of nausea and vomiting associated with motion sickness, surgery and pregnancy [12]. Ginger extracts had different pharmacological effects such as anti-inflammatory [13], anti-oxidant [14], anti-tumor [15] and anti-nephrotoxic effects [16].

Liver is an important organ in the body as it is responsible for removal of toxins and poisons and it is greatly affected by pollutants that cause increase in liver enzymes [17]. The histological study of the liver and immunohistochemical detection of proapoptotic marker bcl-2 antagonist- $X$ protein (BAX) in hepatocytes after metalaxyl administration to albino rats may clarify metalaxyl hazardous effects on liver.

So, the aim of the present study was detection of the histological and immunohistochemical changes that may occur by metalaxyl on liver of adult rat and role of ginger against these changes.

\section{Materials and methods Animals}

In this study, we used thirty healthy adult male albino rats aged 3-4 months and weighed 180-200gm. They were housed in stainless steel cages at Animal House, Faculty of Medicine, Zagazig University at room temperature $\left(25 \pm 1^{\circ} \mathrm{C}\right)$ and illumination (normal light and dark day cycle), fed standard balanced diet and water ad- libitum. One week after acclimatization rats were randomly divided into three equal groups (10 rats in each group). The experiment was performed in accordance to the "Guide for the Care and Use of Laboratory Animals" [18].

\section{Experimental design \\ Group 1 (control group)}

Animals were further subdivided into two equal subgroups: Subgroup 1a: Included animals that received ordinary food and distilled water (the vehicle of metalaxyl) by gastric tube three times/week for successive 4 weeks.

Subgroup $1 \mathrm{~b}$ : included rats that received $100 \mathrm{mg} / \mathrm{kg}$ body weight of ginger orally three times per week by gastric tube for successive 4 weeks.

\section{Group II (Metalaxyl-treated)}

Animals were given metalaxyl at a dose of $130 \mathrm{mg} / \mathrm{kg}$ body weight. Metalaxyl was dissolved in distilled water as a vehicle and given orally by means of gastric tube three times/week for continuous 4 weeks [19]. Metalaxyl was supplied from Central Agricultural Pesticides Laboratory, ARC, Egypt.

\section{Group III (Metalaxyl and ginger treated group)}

Rats were given the same dose of metalaxyl given to animals of group II (130 mg/kg body weight three times/week) and after 1 hour they received ginger dissolved in distilled water by gastric tube at a dose of $100 \mathrm{mg} / \mathrm{kg}$ body weight [16] three times/week for successive 4 weeks. Ginger was purchased from Mepaco-Medifood, (Enshas, Sharkeya, Egypt, Ministry of Health Reg No, 65006).

At the end of the experiment, the rats were anesthetized with $50 \mathrm{mg} / \mathrm{kg}$ body weight sodium pentobarbital by intraperitoneal injection. Intra-cardiac perfusion was done by $2 \%$ glutaraldehyde for partial fixation. Liver specimens from right lobes were dissected out and processed for light, transmission electron microscope and immunohistochemical study.

\section{Histological study}

For light microscope, specimens were fixed in $10 \%$ buffered formalin for 24 hours and processed to prepare 5 um sections stained with hematoxylin and eosin (H\&E) to verify the histological structures [20]. Immunohistochemical staining was done for detection of proapoptotic marker bcl-2 antagonist $X$ protein (BAX) [21,22].

For transmission electron microscope, small pieces $\left(1 \mathrm{~mm}^{3}\right)$ from liver were immediately fixed in $2.5 \%$ glutaraldehyde in $0.1 \mathrm{M}$ cacodylate buffer at $\mathrm{pH} 7.4$ for 24 hours at $4^{\circ} \mathrm{C}$ then the specimens were washed with the buffer, post fixed in $1 \%$ osmium tetroxide in distilled water for $2 \mathrm{~h}$ at $4^{\circ} \mathrm{C}$. Specimens were dehydrated with ascending grades of ethanol and embedded in epoxy resin. After staining the ultrathin sections by uranyl acetate and lead citrate according to Hayat [23], they were examined by using a JEOL, JEM 1010 and JEOL, JEM 1200 EXI I(Japan) electron microscopes (JEOL, Ltd, Tokyo, Japan). Preparation and examination of ultrathin sections were done in the Electron Microscope laboratory of the Histology and cell Biology Department, Faculty of Medicine, Zagazig University, Egypt and in the Electron Microscope Research Laboratory, Faculty of Science, Ain Shams University, Egypt.

For immunohistochemical study, liver sections were deparaffinized in xylene, rehydrated in descending grades of alcohol and immersed in $0.1 \%$ hydrogen peroxide to block the endogenous peroxidase activity. Mouse monoclonal antibody (Ab-14 Golden, Lab Vision Clone B-9, Santa Cruz 
Biotechnolgy Inc., Santa Cruz, California, USA) for BAX was put on each section, the dilution used was 1:50. The antibody was detected by using a biotin-streptavidin system with diaminiobenzide (DAB) that applied for $20 \mathrm{~min}$ at room temp as a chromogen (Dako Carpentaria California USA) for BAX (Dako Corp., code no, k0673, lot 07110). Slides were counterstained with Mayer's hematoxylin (Park Scientific Limited, Northampton, UK), dehydrated and covered by cover slips. In negative control slides, the same system was applied but the primary antibody was not added. The (BAX) cytoplasmic site of reaction was stained brown and nuclei stained blue. This immunohistochemical technique was carried out in the Department of Pathology, Faculty of medicine, Cairo University.

\section{Quantitative morphometric study}

At this study, Leica Qwin 500 Image Analyzer computer system (Leica Microsystem Imaging Solution Ltd., Cambridge, UK) in the image analyzing unit at Pathology Department Faculty of Dentist, Cairo University was used to estimate the area \% for positive BAX immunoreaction in the hepatocytes of all studied groups. Measurements were done from ten non-overlapping fields for each section at $\mathrm{x}-\mathbf{4 0 0}$ magnification to determine the area \% of BAX immunoreaction for detection of apoptosis. For each specimen the mean values and SD were calculated automatically using the image analyzer.

\section{Statistical analysis}

BAX immunoreactions were expressed as mean \pm standard deviation $(X \pm S D)$. The data were subjected to SPSS program (SPSS Inc., Chicago, 111 inois, USA). Statistical analysis was carried out using $T$ test for comparison between subgroups $\mathrm{la}$ and $\mathrm{lb}$ of the control group, one-way analysis of variance (ANOVA) and the least significant difference test (LST) for comparison among groups. The results were considered statistically significant, highly significant and non significant when the $P$ values were $<0.05,<0.001$ and more than 0.05 respectively.

\section{Results \\ Histological results \\ Group I (control group)}

Light microscope examination of liver sections of control subgroups showed the same findings. Hence, we chose the results of subgroup 1a to represent the control group. The liver lobules consisted of anastomosing cords of hepatocytes radiating from the central vein. The hepatocytes appeared acidophilic with central rounded vesicular nuclei. Few cells were binucleated. Blood sinusoids with their kupffer and endothelial cells lining were noticed between the hepatocyte plates (Figure 1). Each portal area contained branches of portal vein and hepatic artery. Bile duct with cuboidal epithelial lining was also seen. Some hepatocytes with pale acidophilic cytoplasm and pale vesicular nuclei were observed (Figure 2). Weak positive granular immunoreaction for BAX was diffusely

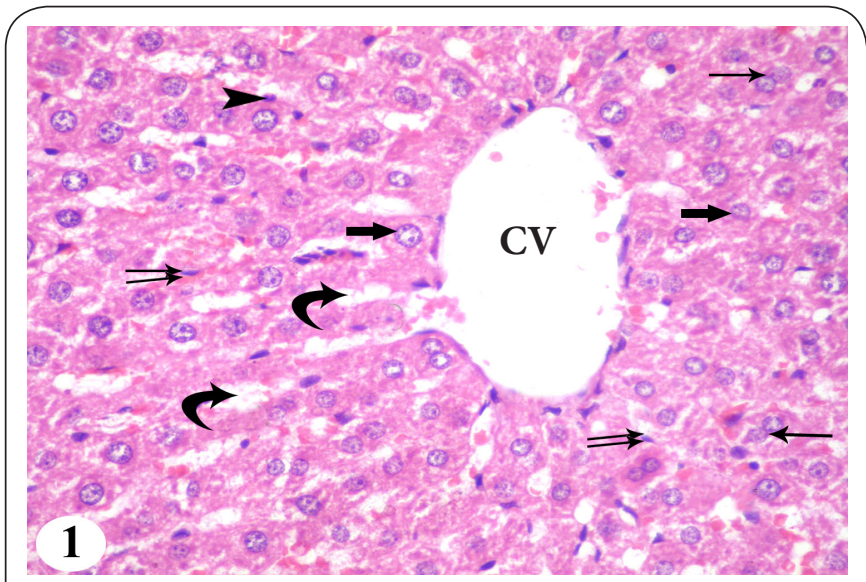

Figure 1. A photomicrograph of a section in the liver of control group showing anastomosing cords of hepatocytes radiating from the central vein $(\mathrm{CV})$. The hepatocytes contain central rounded vesicular nuclei (thick arrows). Few cells are binucleated (thin arrows). Blood sinusoids (curved arrows) with their kupffer (arrow head) and endothelial (double arrows) cells lining are noticed between the hepatocyte plates [H\&E $\times 400]$.

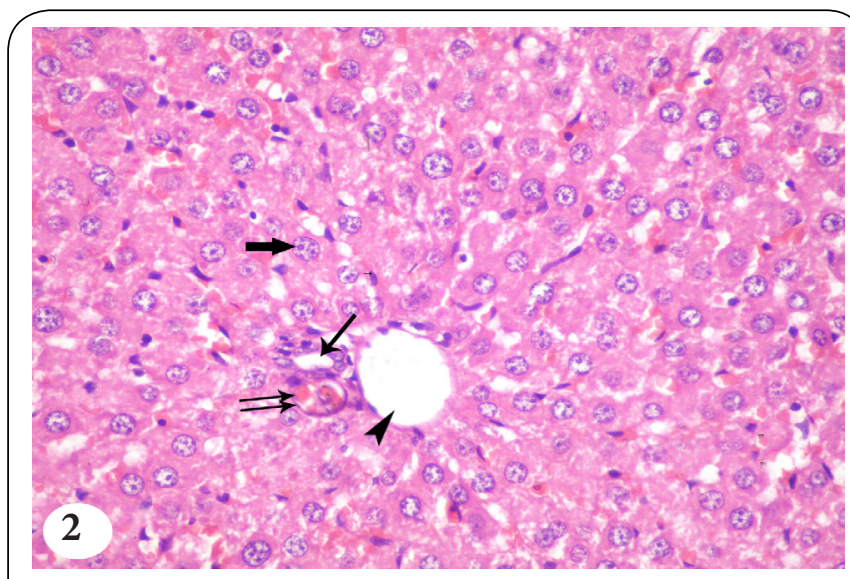

Figure 2. A photomicrograph of a section in the liver of control group showing the portal area with branches of portal vein (arrow head) and hepatic artery (double arrows). Bile duct with cuboidal epithelial lining is also seen (thin arrow). Some hepatocytes with pale acidophilic cytoplasm and pale vesicular nuclei (thick arrow) are observed [H\&E $\times 400]$.

scattered in the cytoplasm of hepatocytes (Figure 3).

Liver sections of control group examined by electron microscope showed hepatocytes with euchromatic nuclei, mitochondria, cisternae of rough ( $\mathrm{rER}$ ) and smooth endoplasmic reticulum (sER) (Figure 4).

\section{Group II (metalaxyl-treated group)}

Focal lobular affection of hepatic tissue was noticed in liver sections of metalaxyl treated group (II). Central veins and blood sinusoids were dilated and congested (Figure 5). Most of the peripheral hepatocytes appeared with cytoplasmic vacuoli- 


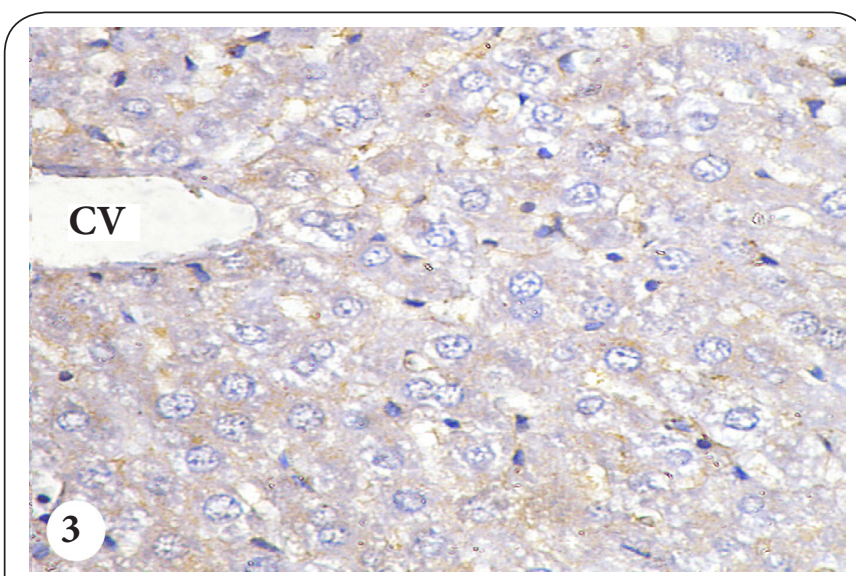

Figure 3. A photomicrograph of a section in a control adult male albino rat's liver showing weak positive granular immunoreactions for BAX diffusely scattered in the cytoplasm of hepatocytes [Immunoperoxidase technique for BAX x400].

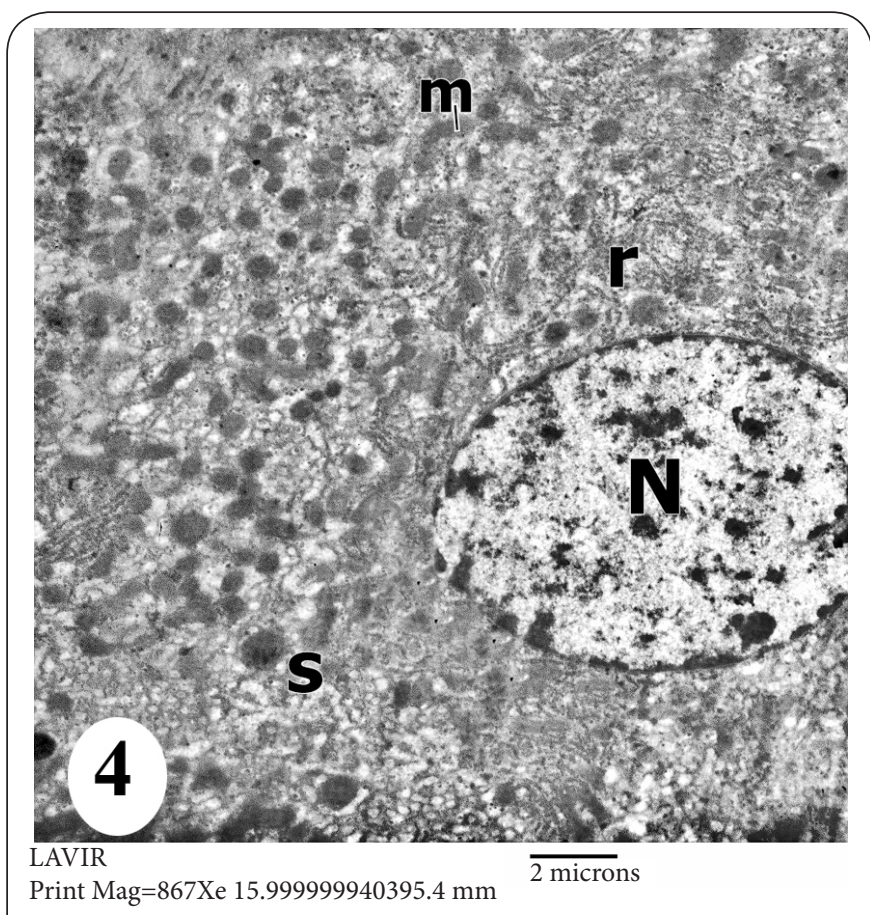

Figure 4. An electron micrograph of a control adult male albino rat's liver showing hepatocyte with euochromatic nucleus $(\mathrm{N})$. The cytoplasm contains mitochondria $(\mathrm{m})$, cisternae of rough (r) and smooth endoplasmic reticulum (s) [Mic. Mag. $\times 8000]$.

zation. Centrilobular hepatocytes contained deeply stained acidophilic cytoplasm and darkly stained nuclei (Figure 6). Enlarged portal area with dilated portal vein, congested hepatic artery, cellular infiltration and numerous bile ductules were detected. One of those bile ductules showed multiple epithelial layers (Figure 7).

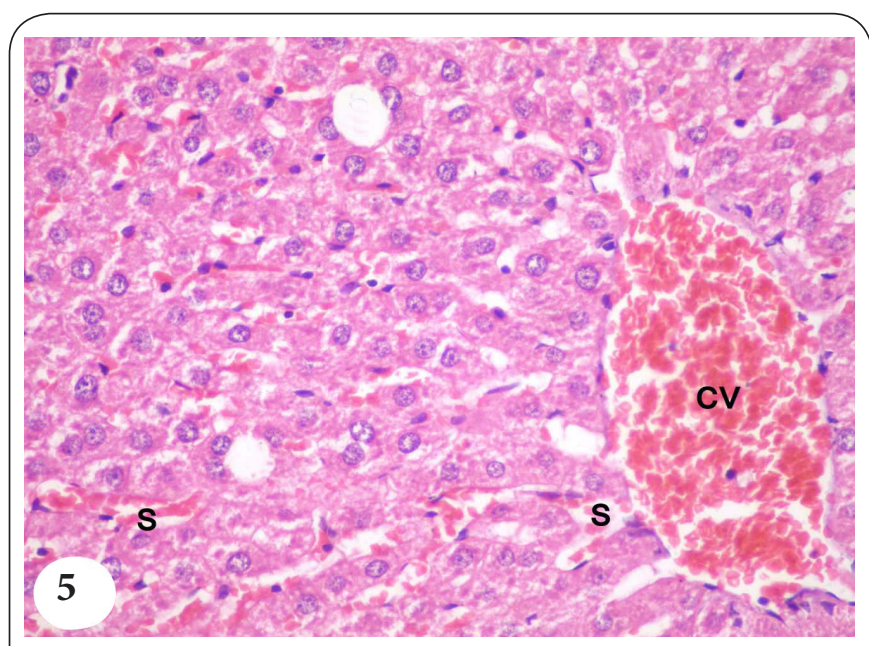

Figure 5. A photomicrograph of a section in the liver of metalaxyl treated group II showing dilated congested central vein $(\mathrm{CV})$ and blood sinusoids $(\mathrm{s})[\mathrm{H} \& \mathrm{E} \times 400]$.

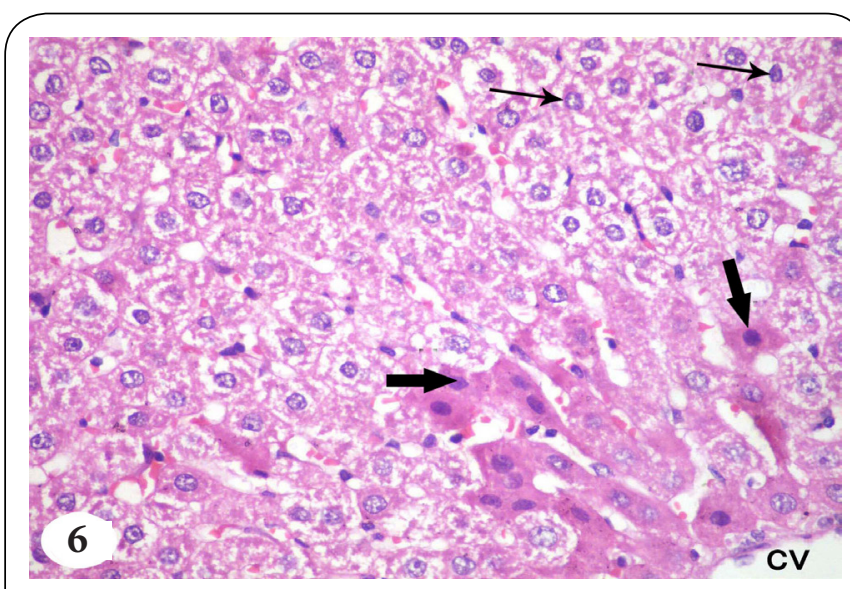

Figure 6. A photomicrograph of a section in the liver of metalaxyl treated group II showing that most of the peripheral hepatocytes (thin arrows) appear with cytoplasmic vacuolization. Centrilobular hepatocytes (thick arrows) contain deeply stained acidophilic cytoplasm and darkly stained nuclei. The central vein $(\mathrm{CV})$ is seen $[\mathrm{H} \& \mathrm{E} \times 400]$.

Immunohistochemical stained sections of metalaxyl treated group revealed strong positive immunoreaction for $B A X$ in nearly all hepatocytes (Figure 8).

Electron microscope examination of the liver sections of metalaxyl treated group II showed hepatocytes with condensed heterochromatin nuclei and irregular nuclear envelops. Electron lucent areas within the cytoplasm, lipid droplets, mitochondria, rough and smooth endoplasmic reticulum were seen. Apoptotic nuclei were also noticed (Figures 9 and 10).

\section{Group III (metalaxyl and ginger)}

Examination of the liver sections of group III, received ginger concomitantly with metalaxyl showed preservation of nearly 


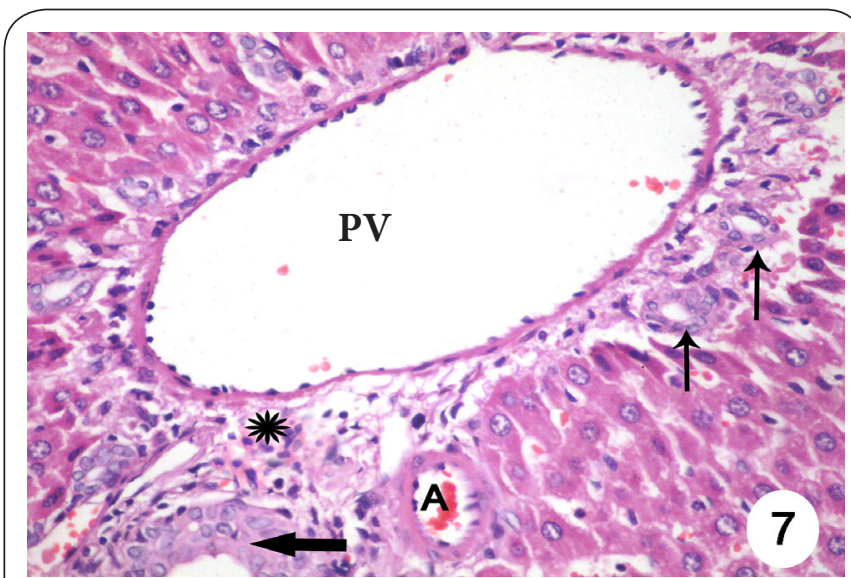

Figure 7. A photomicrograph of a section in the liver of metalaxyl treated group II showing enlarged portal area with branches of dilated portal vein (pv), congested hepatic artery (A), cellular infiltration $\left(^{*}\right.$ ) and numerous bile ductules (thin arrows). One of those bile ductules shows multiple epithelial layers (thick arrow) [H\&E $\times 400]$.

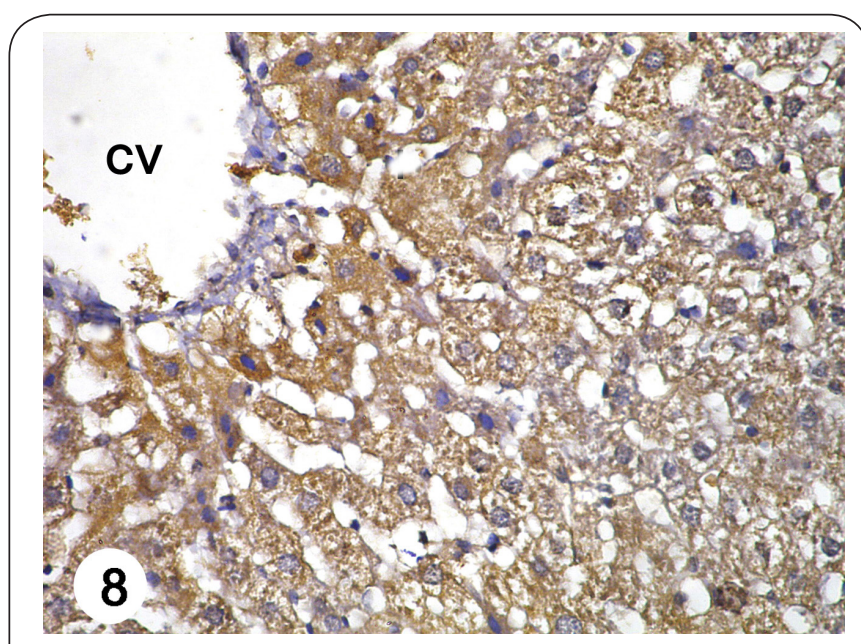

Figure 8. A photomicrograph of a section in the liver of metalaxyl treated group II showing strong positive immunoreaction for BAX in nearly all hepatocytes. Part of dilated central vein $(\mathrm{CV})$ is also seen [Immunoperoxidase technique for $\mathrm{BAX} \times 400]$.

normal hepatic lobular architecture with the presence of slightly dilated congested central veins and blood sinusoids with few cellular infiltration (Figure 11). Portal area contained normal bile duct and congested portal vein. Hepatocytes appeared with acidophilic cytoplasm and vesicular nuclei. Slightly dilated congested blood sinusoids were seen (Figure 12).

Immunohistochemical examination of liver section of group III showed weak positive immunoreaction for BAX in the cytoplasm of most hepatocytes and few cells showed strong reaction (Figure 13).

Electron microscope examination of the liver sections of the group III showed preserved hepatocyte ultrastructure with

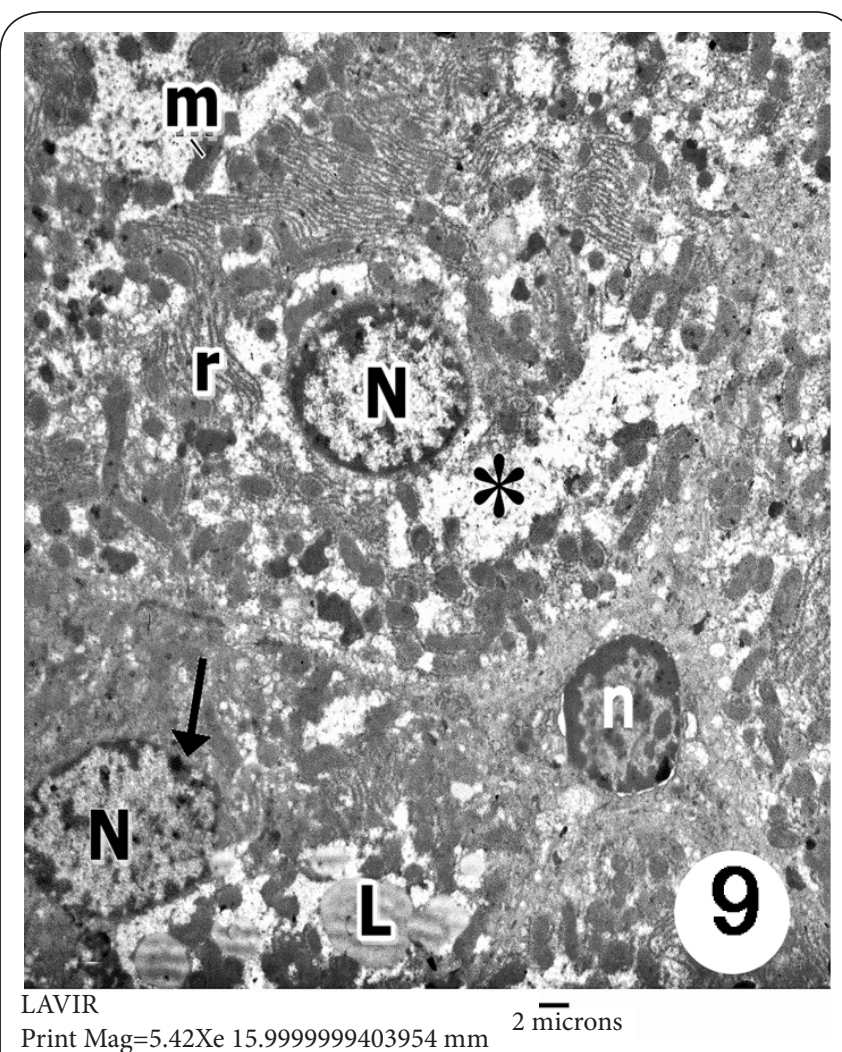

Figure 9. An electron micrograph of a section in the liver of metalaxyl treated group II showing hepatocytes with condensed heterochromatin nuclei $(\mathrm{N})$ and irregular nuclear envelop (arrow). The cytoplasm contains electron lucent area $\left({ }^{*}\right)$, mitochondria $(\mathrm{m})$, lipid droplet $(\mathrm{L})$ and rough endoplasmic reticulum (r). Apoptotic nucleus (n) is also seen [Mic. Mag ×5000].

euchromatic nucleus and two prominent nucleoli (Figure 14). Some hepatocytes were binucleated (Figure 15). Their cytoplasm contained aggregations of rough and smooth endoplasmic reticulum and many mitochondria (Figures 14 and 15). Fat droplets were seen (Figure 15).

\section{Statistical results}

Statistical comparison between subgroups $1 \mathrm{a}$ and $1 \mathrm{~b}$ as regard to the area $\%$ of BAX immunoreaction revealed no significant difference $(P>0.05)$. Therefore, the control group 1a was used for comparison with other groups (Table 1 and Histogram 1).

Metalaxyl treated group (II) showed a statistically significant increase in area \% of BAX immunoreaction when compared to other groups. Also, there is statistical significant difference between group I and II and between groups II and III $(p<0.05)$ but there is no statistical significant difference between group I and III ( $p>0.05$ ) (Table 2 and Histogram 2).

\section{Discussion}

Liver is the primary target organ of metalaxyl toxicity $[19,24]$. 


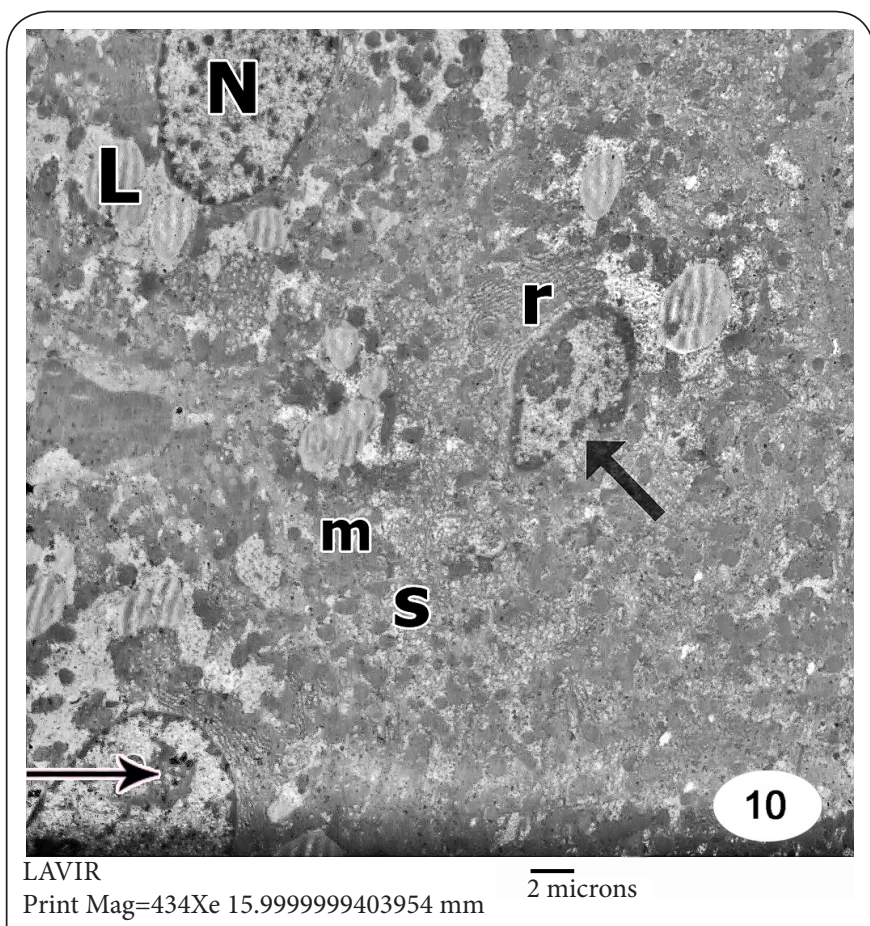

Figure 10. An electron micrograph of a section in the liver of metalaxyl treated group II showing hepatocyte with heterochromatic nucleus and irregular nuclear envelop (arrow). The cytoplasm contains many lipid droplets (L), mitochondria $(\mathrm{m})$, rough $(\mathrm{r})$ and smooth (s) endoplasmic reticulum. Two euchromatic nuclei $(\mathrm{N})$ with prominent nucleolus (thin arrow) are also seen [Mic. Mag $\times 4000]$.

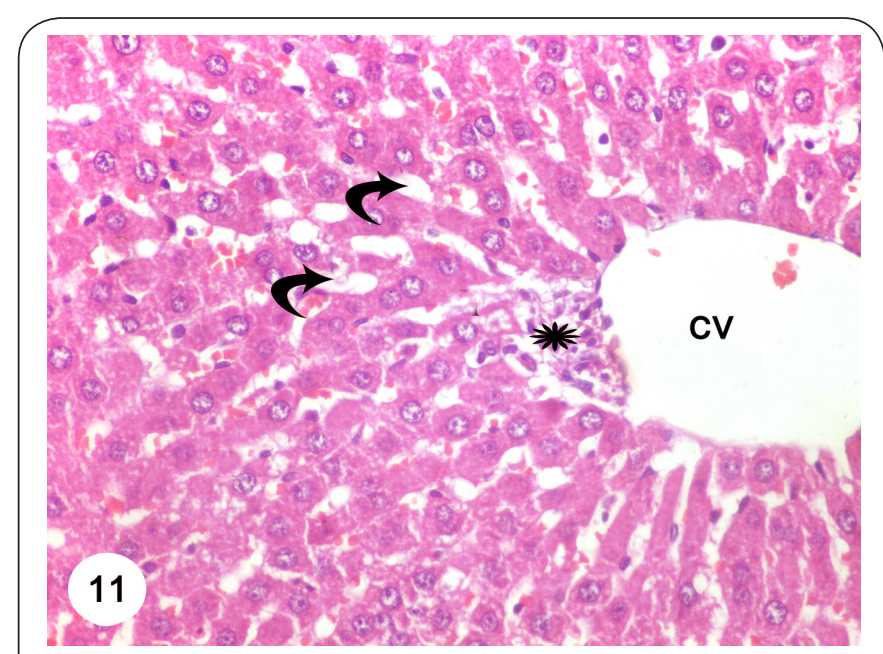

Figure 11. A photomicrograph of a section in the liver of metalaxyl and ginger treated group III showing preservation of nearly normal hepatic lobular architecture with the presence of slightly dilated congested central vein (cv) and blood sinusoids (curved arrows) with few cellular infiltration (*) $[\mathrm{H} \& \mathrm{E} \times 400]$.

Results obtained in the present study showed that metalaxyl induced histopathological alterations in the liver tissue such

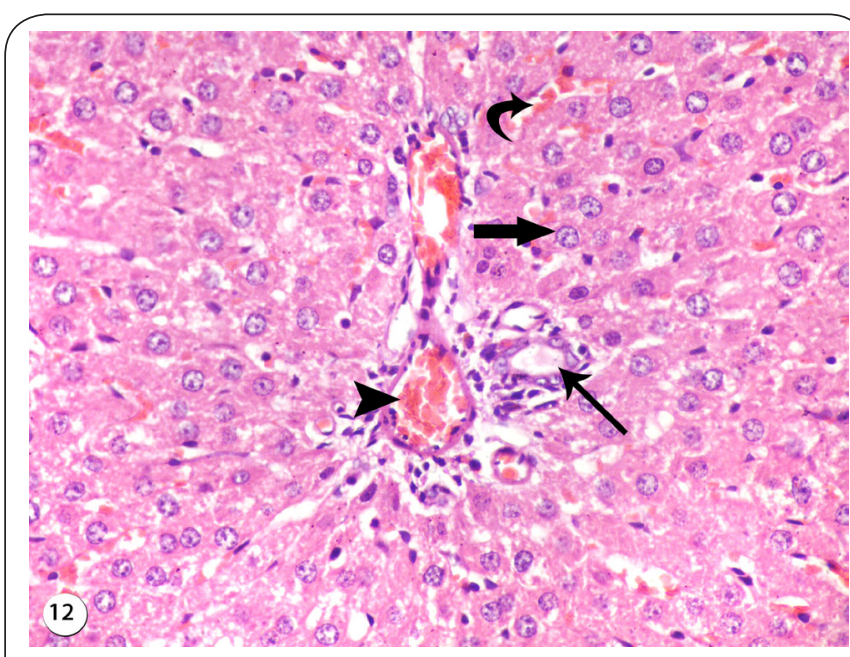

Figure 12. A photomicrograph of a section in the liver of metalaxyl and ginger treated group III showing portal area with congested portal vein (arrow head) and normal bile duct (thin arrow). Hepatocytes appear with acidophilic cytoplasm and vesicular nuclei (thick arrow). Slightly dilated congested blood sinusoids (curved arrow) are seen. [H\&E $\times 400]$.

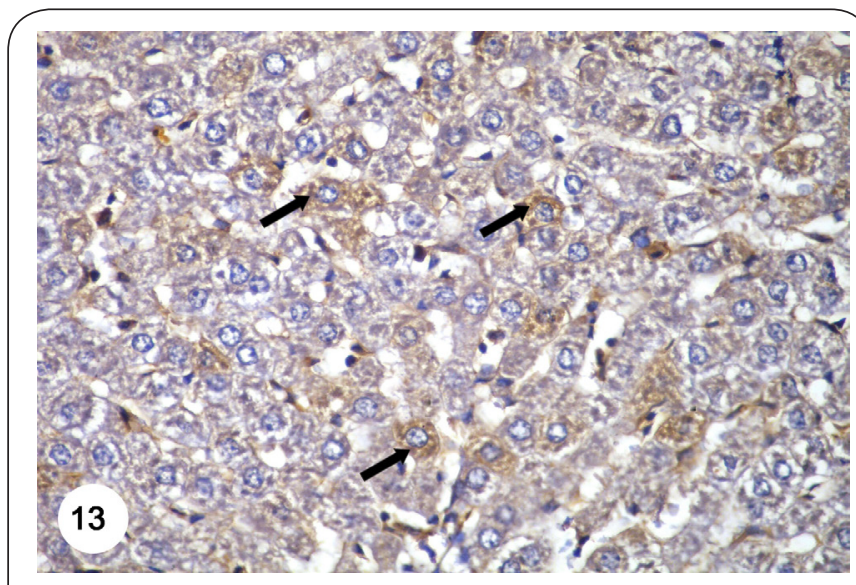

Figure 13. A photomicrograph of a section in the liver of group III showing weak positive immunoreaction for BAX in the cytoplasm of most hepatocytes. Few cells (arrows) appear with strong positive immunoreaction [Immunoperoxidase technique for BAX $\times 400$ ].

Table 1. The mean area $\%$ of BAX immunoreaction of subgroups $1 \mathrm{a}$ and $1 \mathrm{~b}$ of control rats.

\begin{tabular}{llllll}
\hline & $\mathbf{X} \pm$ SD & Range & T test & P-Value \\
\cline { 1 - 5 } Control a & $6.56 \pm 2.58$ & & $4.18-10.06$ & 0.95 & $>0.05$ N.S \\
Control b & $9.08 \pm 5.43$ & $11.17-26.03$ & -- & -- \\
\hline
\end{tabular}

N.S: Non significant; T: Independent sample T test This table shows no significant difference between subgroups $1 \mathrm{a}$ and $1 \mathrm{~b}$ of control rats $(\mathrm{P}>0.05)$.

as congestion of blood vessels, cytoplasmic vacuolization of hepatocytes, apoptosis and necrosis. 
Nabila M. EI-Ghonaimy, Journal of Histology \& Histopathology 2015, http://www.hoajonline.com/journals/pdf/2055-091X-2-9.pdf

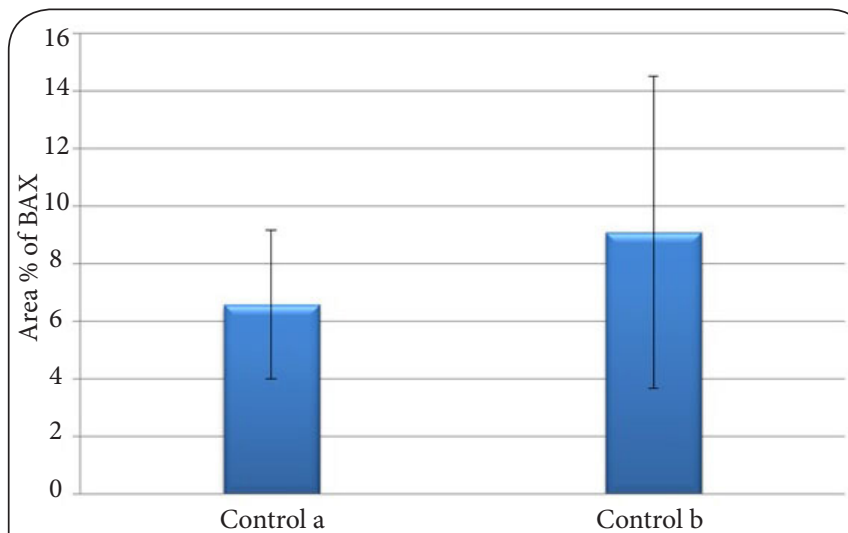

Histogram 1. The mean area $\%$ of BAX of subgroups $1 \mathrm{a}$ and $1 \mathrm{~b}$ of control rats.

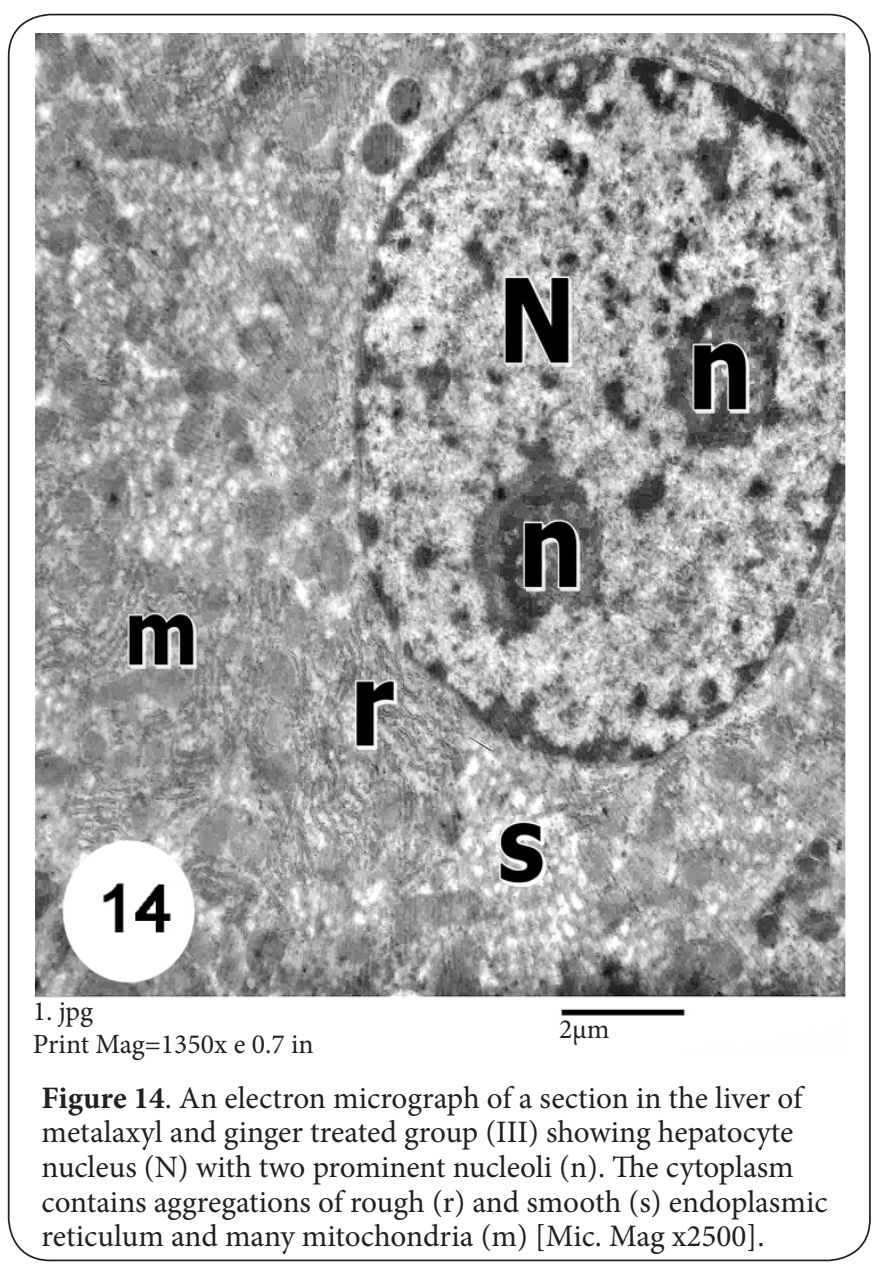

Histological examination of the liver sections of group II revealed different forms of focal lobular affection with congested dilated central vein and blood sinusoids. These changes were also previously observed with metalaxyl $[24,25]$ and other fungicides $[26,27]$. These previous studies referred dilatation to increased levels of prostaglandins that induce

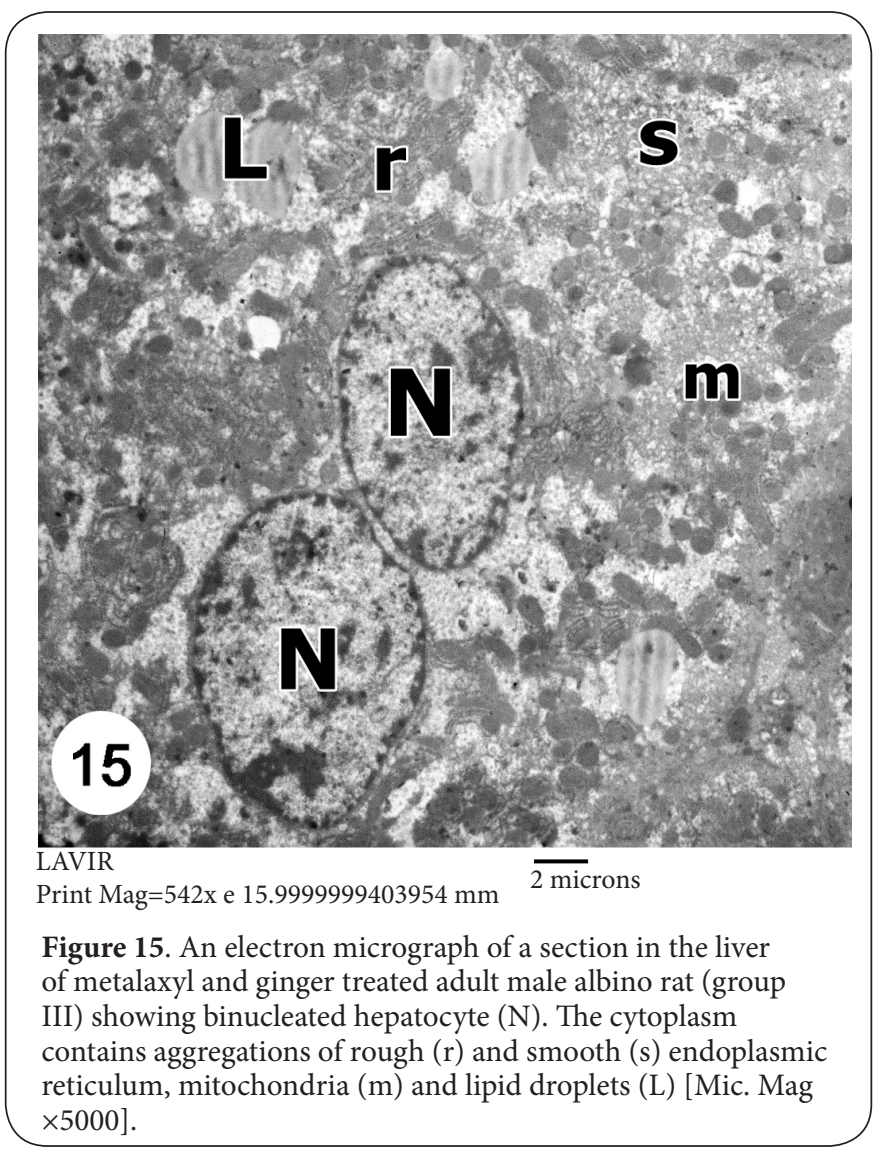

Table 2. The mean area $\%$ of BAX immuoreaction in different studied groups.

\begin{tabular}{llllll}
\hline & X \pm SD & Range & ANOVA & P-Value & LSD \\
\hline $\begin{array}{l}\text { Group 1 } \\
\text { (control a) }\end{array}$ & $6.56 \pm 2.58$ & $4.18-10.06$ & 4.64 & $<0.05^{*}$ & $>0.05$ N.S ${ }^{1}$ \\
Group II & $17.80 \pm 8.94$ & $10.03-32.01$ & -- & -- & $<\mathbf{0 . 0 0 0} 0^{* * 2}$ \\
Group III & $11.10 \pm 4.11$ & $5.94-16.72$ & -- & -- & $<0.05^{\star 3}$ \\
\hline
\end{tabular}

Group I: control; Group II: Metalaxyl-treated; Group III: Metalaxylginger-treated

N.S: Non significant ${ }^{*}$ significant ${ }^{* *}$ highly significant

ANOVA: Analysis of variance test; LSD: Least significant difference 1: Group I versus group III; 2: Group I versus group II; 3: Group II versus group III

This table shows high significant difference between group II and other groups by ANOVA test. By LSD test, there is statistical significant difference between group I and II and also between group II and III but there is no statistical significant difference between group I and III.

smooth muscle relaxation with subsequent vasodilatation. Congestion might be due to loss of fluid from the blood and the vessels engorged with RBC's [28-30].

In liver sections of group II, cytoplasmic vacuolizations were observed in hepatocytes in peripheral regions of liver lobules while those around central veins were less affected. Sigala 


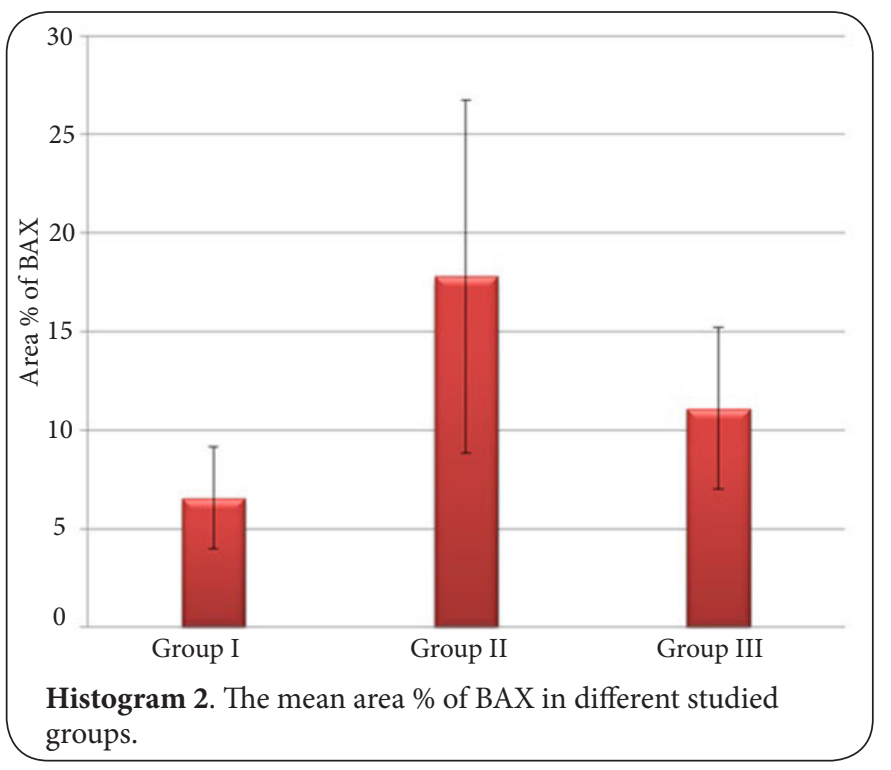

et al., [31] attributed the affection of periportal hepatocytes to rapid uptake of toxins from portal vessels and fast rate of lipid peroxidation.

Lange and Gartzk [32] revealed that cytoplasmic vacuolizations caused by the disruption in microvilli which are normally act as diffusion barrier which inhibit the entrance of hydrophilic and lipophilic xenobiotics into the cytoplasm. Sakr and Shalaby [33] attributed similar findings to the oxidative activity of fungicides with subsequent generation of superoxide anions that cause lipid peroxidation. Lipid accumulation leads to alteration and damage of cellular lipid membranes with paralysis of Na-K pump and hepatocytes edema.

In the current study, numerous bile ductules were detected in the portal areas of group II. The same results were observed by other researchers $[34,35]$ and attributed this proliferation to trans-differentiation of hepatocytes into biliary cells or the mitogenic effect of bile salt stasis on biliary epithelial cells. Cants et al., [36] and Zaghloul [37] reported that endogenous stem cells located at the junction between hepatocytes and the terminal bile ductules may play role in bile duct proliferation.

Cellular infiltration was noticed in the portal areas in liver sections of group II in this study. These observations were in accordance with the results obtained by other studies $[38,39]$ that referred this cellular infiltration to ROS production which indirectly regulate chemokine receptor expression and promote cytokine IL- 6 and IL- 8 which are key modulators of inflammatory response. Other investigators considered that cellular infiltration as a prominent immune response of the body tissues by movement of fluids and leukocytes from the blood into the extravascular tissues $[\mathbf{2 8 , 3 0 ]}$.

Electron microscope study of liver sections of group II in the current work, showed that some hepatocytes contained nuclei with condensed heterochromatin and irregular nuclear envelop which most probably indicating apoptosis. Electron lucent areas in their cytoplasm were also seen revealing necrosis. Similar results were observed by Hashem [10] who correlated apoptosis and necrotic cell death of hepatocytes in metalaxyl treated rats with high blood and tissue levels of malondialdehyde which is a marker for oxidative stress.

In the current study, ginger treatment simultaneously with metalaxyl in the group III leads to preservation of the liver histological structure with slight dilatation and congestion of blood vessels and few cellular infiltration. Ultrastructurally, hepatocytes showed normal appearance of their nuclei and cytoplasmic organelles. The hepato-protective effect of ginger may be due to its volatile oils which had anti-inflammatory, anti-analgesic and immunomodulatory effects $[11,13]$. Previous reports have documented the ability of ginger ingredients as gingerols to inhibit prostaglandins and leukotrienes synthesis $[16,19]$. It was reported that ginger have hepatoprotective effect due to its antioxidant activity to reduce the activity of free radicals [19]. Some lipid droplets were noticed in the cytoplasm of some hepatocytes of group III. This was explained as a defense mechanism by which hepatocytes attempt to collect all toxic compounds invading the cells prior to excretion [10].

Immunohistochemical study showed strong positive immunoreaction of BAX in nearly all hepatocytes in the affected areas of group II compared to the control group indicating that these cells are susceptible to apoptosis. Statistical analysis revealed significant increase in the area \% of BAX-in group II when compared with other groups. Other studies reported the same results of BAX immunoreaction in mouse liver [22] and thymus [40].

Apoptosis is a mode of cell death which occurred physiologically [22]. Chen et al., [41] noticed high expression of BAX protein in chronic hepatitis. Other researchers referred apoptosis of hepatocytes to activation of tumor protein (p53) and release of cytochrome $\mathrm{c}$ from the damaged mitochondria to the cytoplasm of hepatocytes [42].

The organophosphorus pesticides induced apoptosis by activation of intracellular cysteine-aspartic acid protease (caspase-3) [43] or by oxidative stress and ROS which lead to DNA damage $[44,45]$.

Fungicides induced a significant decrease in the serum antioxidant enzymes activities, superoxide dismutase and increase in lipid peroxidation in albino rats $[27,46]$. Marked reduction in antioxidant enzymes activities and tissue glutathione contents resulted in oxidative damage of tissues and leads to apoptosis in cellular systems, especially hepatocytes $[7,47]$.

In the current study, immunodetection of BAX protein in liver sections of group III showed weak positive reaction in most of hepatocytes compared to the strong positive reaction observed in group II and significant decrease in the mean area $\%$ of BAX when compared with group II suggesting that ginger reduced apoptosis. These findings were supported by previously performed clinical and experimental investigations in liver of mice [19], testis [48] and kidney [16] that have shown 
that ginger has a protective effect against oxidative damage and apoptosis through its antioxidant properties.

Lamfon [19] reported that the underground rhizome of ginger contained many flavonoids with anti-oxidant activity which prevents free radicals generation. Also, previous investigators demonstrated that ginger oil had a dominative protective effect on DNA damage and might act as a scavenger of oxygen radicals $[49,50]$.

\section{Conclusion}

Metalaxyl causes histological and immunohistochemical changes in liver probably through oxidative stress. Ginger therapy could ameliorate these changes in liver and this may be attributed to its antioxidant and free radicals scavenging properties. This study showed that ginger supplementation may minimize the hazardous effects of metalaxyl.

\section{Competing interests}

The author declares that he has no competing interests.

\section{Acknowledgement}

I would like to thank dr. Dalia ELRobi for morphometrical aid and dr. Dina Sameh for statistical aid.

Publication history

Editors: Lingyan Wang, Oregon Health \& Science University, Portland.

Paola Castrogiovanni, University of Catania, Italy.

EIC: Giuseppe Musumeci, University of Catania, Italy.

Received: 10-Feb-2015 Final Revised: 15-Mar-2015

Accepted: 08-Apr-2015 Published: 15-Apr-2015

\section{References}

1. Sukul P and Spiteller M. Metalaxyl: persistence, degradation, metabolism, and analytical methods. Rev Environ Contam Toxicol. 2000; 164:1-26. | PubMed

2. Pattanasupong $A$, Nagase $H$, Sugimoto $E$, Hori $Y$, Hirata $K$, Tani K, Nasu M and Miyamoto K. Degradation of carbendazim and 2,4-dichlorophenoxyacetic acid by immobilized consortium on loofa sponge. J Biosci Bioeng. 2004; 98:28-33. I Article I PubMed

3. Ding F, Li XN, Diao JX, Sun Y and Zhang L. Chiral recognition of metalaxyl enantiomers by human serum albumin: evidence from molecular modeling and photophysical approach. Chirality. 2012; 24:471-80. I Article I PubMed

4. Dasgupta S, Banerjee K, Dhumal K.N and Adsule P.G. Optimization of detection conditions and single-laboratory validation of a multiresidue method for the determination of 135pesticides and25organicpollutants in grapes and wine by gas chemotherapy time-of -flightmass spectrometry. JAOAC Int. 2011; 94:273-85.

5. Hrelia P, Maffei F, Fimognari C, Vigagni F and Cantelli-Forti G. Cytogenetic effects of Metalaxyl on human and animal chromosomes. Mutat Res. 1996; 369:81-6. | Article I PubMed

6. Demsia G, Vlastos D, Goumenou M and Matthopoulos DP. Assessment of the genotoxicity of imidacloprid and metalaxyl in cultured human Iymphocytes and rat bone-marrow. Mutat Res. 2007; 634:32-9. | Article I PubMed

7. Al-Amoudi W.M. Haematological and biochemical effects of effects of metalaxyl fungicide on albino mice. American Journal of Biochemistry. 2012; 2:62-66. I Article

8. Rao M.V, Sundar R.S and Chawla SI. Reproductive toxicity of a fungicide combination (metalaxyl-mancozeb) in adult male rats. $J$ Cell and Tissue Res. 2005; 5:299-302.
9. Mehra BI, Priyanka Sharma, Utkash Kaushik and Joshi SC. Effect of fytolan on testicular functions and sex hormones. World Journal of Pharmacy and Pharmceutical Sciences. 2014; 3:817-829. I Article

10. Hashem H.E. Light and Electron Microscopic Study of the Possible Protective Effect of Nigella Sativa on Metalaxyl Induced Hepatotoxicity in Adult Albino Rats. Cell Science \& Therapy. 2012; 3:1-6. I Pdf

11. Lantz RC, Chen GJ, Sarihan M, Solyom AM, Jolad SD and Timmermann $B N$. The effect of extracts from ginger rhizome on inflammatory mediator production. Phytomedicine. 2007; 14:123-8. | Article | PubMed

12. Gilani AH and Rahman AU. Trends in ethnopharmocology. J Ethnopharmacol. 2005; 100:43-49. | Article | PubMed

13. Young HY, Luo YL, Cheng HY, Hsieh WC, Liao JC and Peng WH. Analgesic and anti-inflammatory activities of [6]-gingerol. J Ethnopharmacol. 2005; 96:207-10. | Article | PubMed

14. Stoilova I, Krastanov A, Stoyanova A, Denev P and Gargova S. Antioxidant activity of a ginger exteract (Zingiber Officinale). Food Chem. 2007; 102:764-770. | Article

15. Shukla $Y$ and Singh $M$. Cancer preventive properties of ginger: a brief review. Food Chem Toxicol. 2007; 45:683-90. | Article | PubMed

16. Sakr S.A, Lamfon A.H and Essawy A.E. Ginger (Zingiber Officinale) extract ameliorates metalaxyl fungicide induced nephrotoxicity in albino mice. African Journal of Pharmacy and Pharmacology. 2011; 5:104-112. I $\underline{\text { Article }}$

17. Kumar A, Tomar M, Kumar S and Maharshi K. Effect of sub-lethal doses of imidacloprid on histological and biochemical parameters in female albino mice. ISOR Journal of Environmental Science, Toxicology and Food Technology. 2014; 8:9-15. I Website

18. Institute of Laboratory Animal Resources. "Guide for the Care and Use of Laboratory Animals". (National Academy Press, Washington, DC). 1996.

19. Lamfon H.A. Protective effect of ginger (Zingiber officinale) against metalaxyl induced hepatotoxicity in albino mice. J Am Sci. 2011; 7:10931100. | Article

20. Bancroft JD and Gamble M. Theory and Practice of Histological Technique. 6th ed. Churchill Livingstone, New York, London. 2008; 176177.

21. Kiernan J. Histological and histochemical methods: theory and practice. 3rd ed., Butterworth-Heinemann, Oxford, Boston and New Delhi. 2000; 129-139. | Book

22. Sakr S.A and Abdel-Samie H.A. Apoptosis related protein Bax in liver of metalaxyl fungicide-treated mice. The effect of antox. Ozean J Appl Science. 2008; 1:17-27. | Pdf

23. Hayat M.A. Principles and techniques of electron microscopy:biological applications 4-th ed. Edinburg, UK: Cambridge University Press. 2000; 37-59.

24. Okdah Y.A. Effect of antox on metalaxyl fungicide induced histological and histochemical changes in liver of albino mice. J Egypt Germ Soc Zool. 2005; 48:205-216.

25. Sakr SA and Lamfon $H$ A. Effect of green tea on metalaxyl fungicide induced liver injury in albino mice. Oxford Res. Forum. J. 2005; 2:65-69.

26. Sakr SA, Mahran HA and Abo-Elyazd SM. Effect of DDB on mancozeb fungicide induced ultrastructural and biochemical changes in the liver of albino mice. Proceedings of the 9-th International Conference on Environmental Science and Technology Rhodes island Greece. 2005; 1:809-816. | Article

27. Sakr SA. Ameliorative effect of ginger (Zingiber officinale) on mancozeb fungicide induced liver injury in albino rats. Australian J. Basic Appl. Sci. 2007; 14:650-656. I Pdf

28. Walter J.B and Israel M. Inflammation in Walter. JB, Talbot IC, editors Walter and Israel general pathology 7-th ed Churchill Livingstone. New York. 1996; 167. I Book

29. Selmanoglu G, Barlas N, Songur S and Kockaya EA. Carbendazim-induced haematological, biochemical and histopathological changes to the liver and kidney of male rats. Hum Exp Toxicol. 2001; 20:625-30. | Article | PubMed 
Nabila M. EI-Ghonaimy, Journal of Histology \& Histopathology 2015, http://www.hoajonline.com/journals/pdf/2055-091X-2-9.pdf

30. Mohany M, Badr G, Refaat I and El-Feki M. Immunological and histological effects of exposure to imidacloprid insecticide in male albino rats. African Journal of Pharmacy and Pharmacology. 2011; 5:2106-2114. | Website

31. Sigala F, Kostopanagiotou G, Andreadou I, Kavatzas N, Felekouras E, Sigalas P, Bastounis E and Papalambros E. Histological and lipid peroxidation changes after administration of 2-acetylaminofluorene in a rat liver injury model following selective periportal and pericentral damage. Toxicology. 2004; 196:155-63. | Article | PubMed

32. Lange $K$ and Gartzke J. Microvillar cell surface as a natural defense system against xenobiotics: a new interpretation of multidrug resistance. Am J Physiol Cell Physiol. 2001; 281:C369-85. | Article | PubMed

33. Sakr S.A and Shalaby S.Y. Metiram-induced histological and histochemical alterations in liver and kidney of pregnant mice. Life Science Journal. 2012; 9:71-76. I Pdf

34. Michalopoulos GK, Barua L and Bowen WC. Transdifferentiation of rat hepatocytes into biliary cells after bile duct ligation and toxic biliary injury. Hepatology. 2005; 41:535-44. | Article I PubMed Abstract | PubMed Full Text

35. Chen YK, Zhao XX, Li JG, Lang S and Wang YM. Ductular proliferation in liver tissues with severe chronic hepatitis B: an immunohistochemical study. World J Gastroenterol. 2006; 12:1443-6. I Article I PubMed Abstract | PubMed Full Text

36. Cantz T, Manns MP and Ott M. Stem cells in liver regeneration and therapy. Cell Tissue Res. 2008; 331:271-82. | Article | PubMed Abstract | PubMed Full Text

37. Zaghloul, M S. Histological study on the effects of electromagnetic field on the liver of albino rats 2.Origin and ultrastructural evaluation of the early proliferated bile duct epithelium- like cells. Egypt J.Histol. 2010; 33:279-287. | Pdf

38. Sakr SA and Al-Amoudi W. Protective effect of silymarin on metrium fungicide-induced hepatotoxicity in albino rats. Research Journal of Pharmaceutical, Biological and Chemical Sciences. 2012; 3:691-699. I Pdf

39. Rizvi AA. Cytokine biomarkers, endothelial inflammation, and atherosclerosis in the metabolic syndrome: emerging concepts. Am J Med Sci. 2009; 338:310-8. I Article I PubMed

40. Sakr S.A and Lamfon H.A. Metalaxyl fungicide induced oxidative stress and apoptosis in mouse thymus: the effect of antox. Int.J.Immunological Studies. 2010; 2:135-149. | Article

41. Chen NL, Bai L, Li L, Chen PL, Zhang C, Liu CY, Deng T, Chen H, Jia KM and Zhou ZQ. Apoptosis pathway of liver cells in chronic hepatitis. World J Gastroenterol. 2004; 10:3201-4. I Article I PubMed

42. Ayed-Boussema I, Bouaziz C, Rjiba K, Valenti K, Laporte F, Bacha H and Hassen W. The mycotoxin Zearalenone induces apoptosis in human hepatocytes (HepG2) via p53-dependent mitochondrial signaling pathway. Toxicol In Vitro. 2008; 22:1671-80. | Article | PubMed

43. Li Q, Kobayashi M and Kawada T. Organophosphorus pesticides induce apoptosis in human NK cells. Toxicology. 2007; 239:89-95. | Article | PubMed

44. Calviello G, Piccioni E, Boninsegna A, Tedesco B, Maggiano N, Serini $\mathrm{S}$, Wolf $\mathrm{FI}$ and Palozza P. DNA damage and apoptosis induction by the pesticide Mancozeb in rat cells: involvement of the oxidative mechanism. Toxicol Appl Pharmacol. 2006; 211:87-96. | Article | PubMed

45. Franco R, Sanchez-Olea R, Reyes-Reyes EM and Panayiotidis MI. Environmental toxicity, oxidative stress and apoptosis: menage a trois. Mutat Res. 2009; 674:3-22. I Article I PubMed

46. Adjrah Y, Karou S.D, Agbonon A, Eklu-gadegbeku,K, de-Souza C and Gbeassor. Toxicological assessment of effect of mancozeb-treated lettuce (Lactuca sativa) on Wister rat liver. Ethiopian Journal of Enviromental Studies and Management. 2013; 6:67-73. I Pdf

47. Nakatani T, Tawaramoto M, Opare Kennedy D, Kojima A and Matsui-Yuasa I. Apoptosis induced by chelation of intracellular zinc is associated with depletion of cellular reduced glutathione level in rat hepatocytes. Chem Biol Interact. 2000; 125:151-63. | Article | PubMed
48. Sakr S.A and Shlaby S.Y. Ginger extract protects metalaxyl-induced histomorphological and histochemical alterations in testes of albino mice. Journal of Applied Pharmaceutical Science. 2011; 1:36-42. I Pdf

49. Abdel-Azeem AS, Hegazy AM, Ibrahim KS, Farrag AR and El-Sayed EM. Hepatoprotective, antioxidant, and ameliorative effects of ginger (Zingiber officinale Roscoe) and vitamin E in acetaminophen treated rats. J Diet Suppl. 2013; 10:195-209. | Article | PubMed

50. Arafa N.M.S and Ali E.H.A. Protective role of either ginger or lipoic acid on senile female rats. Neuroscience. 2014; 3:22-28.

\section{Citation:}

Ei-Ghonaimy NM. Role of ginger (zingiber officinale) against metalaxyl induced hepatotoxicity in male albino rats: a histological and immunohistochemical study. J Histol Histopathol. 2015; 2:9.

http://dx.doi.org/10.7243/2055-091X-2-9 